\title{
Rare lung diseases III: Pulmonary Langerhans' cell histiocytosis
}

\author{
Stephen $C$ Juvet $M D^{1}$, David Hwang MD PhD², Gregory P Downey $\mathrm{MD}^{3}$
}

SC Juvet, D Hwang, GP Downey. Rare lung diseases III: Pulmonary Langerhans' cell histiocytosis. Can Respir J 2010;17(3):e55-e62.

Pulmonary Langerhans' cell histiocytosis (PLCH) is an unusual cystic lung disease that is also characterized by extrapulmonary manifestations. The current review discusses the presenting features and relevant diagnostic testing and treatment options for PLCH in the context of a clinical case. While the focus of the present article is adult PLCH and its pulmonary manifestations, it is important for clinicians to distinguish the adult and pediatric forms of the disease, as well as to be alert for possible extrapulmonary complications. A major theme of the current series of articles on rare lung diseases has been the translation of insights gained from fundamental research to the clinic. Accordingly, the understanding of dendritic cell biology in this disease has led to important advances in the care of patients with PLCH.

Key Words: Histiocytes; Interstitial lung disease; Pulmonary cysts; Rare lung diseases

\section{CASE PRESENTATION}

A 29-year-old woman presented with symptoms of sharp, right-sided chest pain and an aching pain on the left side of her head. Otherwise, she was healthy, with no constitutional symptoms. On examination, there was no evidence of cyanosis, clubbing or lymphadenopathy. Focal tenderness was identified anteriorly in the right lower parasternal region. Chest auscultation revealed vesicular breath sounds with no adventitious sounds; percussion was normal.

A chest $\mathrm{x}$-ray revealed evidence of a cystic right eighth rib lesion, as well as diffuse nodular opacities in both lung fields (Figure 1). Plain skull $\mathrm{x}$-rays showed a lytic lesion in the left parietal bone.

The patient was previously healthy and did not take regular medications. She had smoked one pack of cigarettes daily since the age of 17 years, but she denied having had dyspnea, cough, wheeze or hemoptysis. She was from southwestern Ontario and had not travelled to regions with a high prevalence of tuberculosis or endemic fungi. She did not have risk factors for HIV infection, any personal or family history of lung disease, and no unusual occupational or recreational exposures.

A computed tomography (CT) scan of the chest revealed diffuse, thick-walled cysts and nodules without associated lymphadenopathy or pleural effusions (Figure 2). The cystic rib lesion was also visualized. A whole body bone scan revealed increased uptake in the left parietal bone and right eighth rib; no additional lytic lesions were identified. Pulmonary function

\section{Les maladies pulmonaires rares III : L'histiocytose pulmonaire à cellules de Langerhans}

\begin{abstract}
L'histiocytose pulmonaire à cellules de Langerhans (HPCL) est une maladie kystique pulmonaire inhabituelle caractérisée par des manifestations extrapulmonaires. La présente analyse expose les caractéristiques à la présentation, les tests diagnostiques pertinents et les possibilités thérapeutiques à l'égard des cas cliniques d'HPCL. Elle porte sur l'HPCL chez l'adulte et sur ses manifestations pulmonaires, mais il est important que les cliniciens distinguent les formes adulte et pédiatrique de la maladie et qu'ils soient à l'affût des possibilités de complications extrapulmonaires. L'un des grands thèmes de la présente série d'articles sur les maladies pulmonaires rares a consisté à transférer les observations tirées de la recherche fondamentale en clinique. De même, la compréhension de la biologie des cellules dendritiques dans cette maladie a suscité d'importantes avancées dans les soins aux patients ayant une HPCL.
\end{abstract}

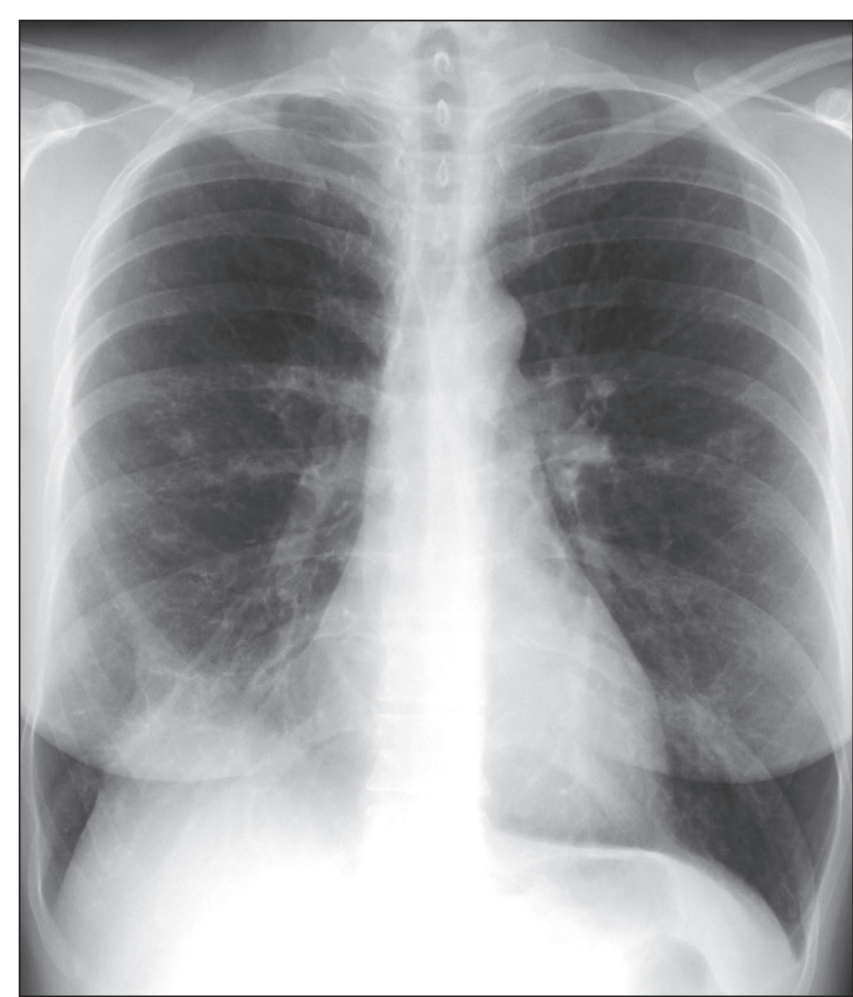

Figure 1) Posteroanterior chest radiograph showing bilateral nodular opacities, some of which show cavitation

${ }^{1}$ Division of Respirology and Clinician-Scientist Training Program, Department of Medicine; ${ }^{2}$ Department of Laboratory Medicine and Pathobiology, and Toronto General Hospital/University Health Network, Toronto, Ontario; ${ }^{3}$ Departments of Medicine, Pediatrics, and Immunology, National Jewish Health and University of Colorado, Aurora, Colorado, USA

Correspondence: Dr Gregory P Downey, National Jewish Health, K701b-1400 Jackson Street, Denver, Colorado 80206, USA.

Telephone 303-398-1436, fax 303-270-2243, e-mail downeyg@njhealth.org 


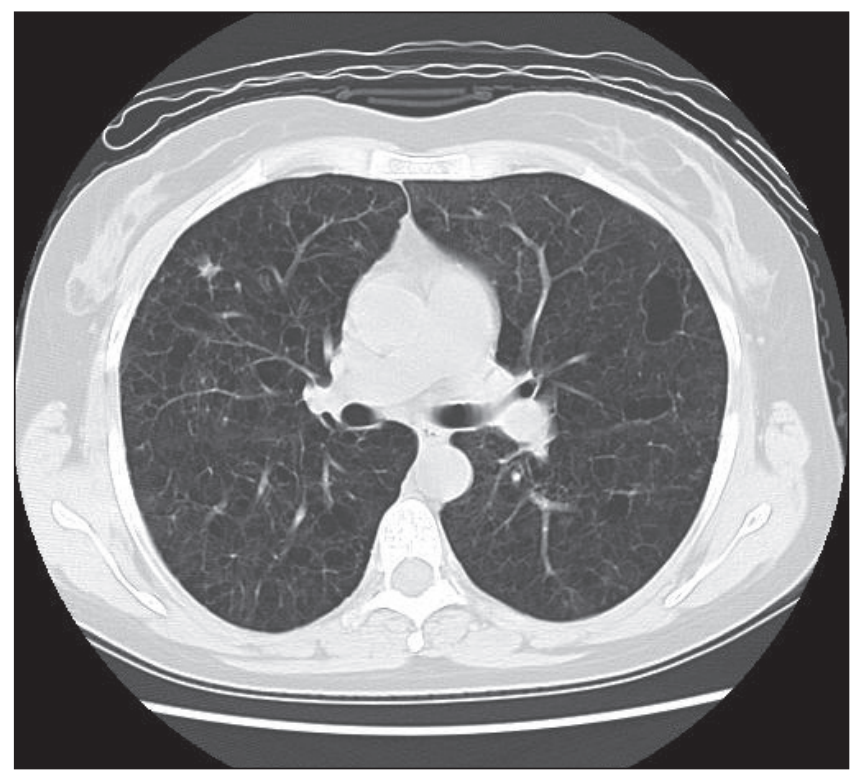

Figure 2) Computed tomography image illustrating many bilateral lung cysts of varying shapes and sizes, and an example of a stellate nodule located in the right middle lobe. Lymphadenopathy and pleural effusions were absent

tests revealed mild mixed restriction and obstruction, with a marked reduction in the diffusing capacity ( $41 \%$ of predicted).

Bronchoscopy revealed normal airways. A bronchoalveolar lavage (BAL) specimen was negative for microorganisms; the differential cell count revealed $92 \%$ macrophages. A surgical biopsy of the right middle lobe was performed. During the procedure, many palpable nodules were noted in the lung parenchyma. Microscopic examination of the biopsy specimens revealed focal airway-centred cellular infiltrates and surrounding cyst formation. These regions contained cells with convoluted nuclear membranes staining strongly for S100 antigen. On electron microscopy, Birbeck granules were visualized within these cells and, therefore, were identified as Langerhans' cells (LCs). Eosinophils were present and a background pattern of desquamative interstitial pneumonitis was also seen. A diagnosis of LC histiocytosis (LCH) was made.

\section{PULMONARY LCH}

\section{Classification}

LCH is a disorder characterized by the accumulation of LCs in various organs and tissues (1,2). LCs are bone marrow-derived dendritic cells (DCs) whose normal physiological function is the processing and presentation of skin-derived antigens. In $\mathrm{LCH}$, aberrant accumulation of LCs often results in granuloma formation with eosinophilic infiltration (3) and, hence, the term 'eosinophilic granuloma' has often been applied to these diseases. Clinicians should keep in mind that LCH is part of a spectrum of other histiocytic disorders. The Histiocyte Society classification, published in 1997 (2), categorizes these illnesses into group I (LCH), group II (non-Langerhans, mononuclear phagocyte histiocytic proliferations such as Erdheim-Chester disease and Rosai-Dorfman disease) and group III, which consists of malignant histiocytic disorders. In the present article, attention will be focused on pulmonary LCH (PLCH); however, we begin by placing it within the context of a group I classification.
Group I disorders (ie, LCH) are further classified by the extent of organ system involvement at presentation. Single-site disease, which usually occurs in young adults, typically affects bone, brain or the lungs. In contrast, acute-onset, diffuse LCH involving multiple organ systems (previously known as LettererSiwe disease), occurs mainly in children and has a relatively poor prognosis. Between these two extremes is multifocal LCH, previously called Hand-Schüller-Christian syndrome. This disease typically occurs in older children and adolescents, and has a more favourable course than diffuse LCH.

Therefore, PLCH may occur as an isolated disorder or as a component of a multisystem illness. In the latter setting, the pulmonary disease does not usually dominate the clinical picture at presentation, but can contribute to morbidity and mortality $(4,5)$. Adults with $\mathrm{LCH}$ are more likely to have isolated PLCH; however, as in our case, patients presenting with this disorder have extrapulmonary involvement in up to approximately $15 \%$ of cases $(6,7)$.

\section{Epidemiology}

Limited epidemiological data regarding LCH and PLCH are available. An annual incidence of LCH of approximately three to five cases per million children per year was reported in a Danish registry (8). In adults, $\mathrm{LCH}$ is also rare, but its prevalence and incidence cannot be determined because of the lack of population-based studies. However, a Swiss review of hospital records between 1970 and 1991 identified only 19 cases (9).

PLCH is also unusual among diffuse parenchymal lung diseases $(5,10)$. Two large series $(11,12)$ including hundreds of patients undergoing surgical lung biopsies for interstitial disease revealed a prevalence of PLCH of only $3 \%$ to $5 \%$ among these patients.

PLCH was once considered to be more common in men (13), but more recently has been reported at least as frequently in women as in men $(5,14)$. The latter finding is believed to have resulted from changes in the epidemiology of smoking over the past few decades (5). Indeed, smoking is strongly associated with PLCH; at least $90 \%$ of PLCH patients are current smokers $(3,13-17)$.

\section{Clinical features of PLCH in adults}

$\mathrm{LCH}$ presenting in adults is nearly always PLCH (5). Conversely, PLCH is most frequently an isolated disease process occurring in a young adult smoker. Consequently, PLCH should be considered to be a distinct entity separate from other histiocytic disorders. Another reason for this assertion is that PLCH is very strongly associated with tobacco smoking, with more than $90 \%$ of patients reporting regular tobacco use $(3,7)$. Nevertheless, clinicians caring for adult patients with PLCH must be alert to the possibility of extrapulmonary disease manifestations as well. The most likely extrapulmonary features in PLCH patients are cystic bone lesions, diabetes insipidus from posterior pituitary involvement and skin lesions $(7,17)$.

Patients with PLCH may present with a nonproductive cough or dyspnea, but these symptoms are often insidious in onset and patients may attribute them to smoking. However, patients may be entirely asymptomatic and present only with an abnormal chest radiograph. A third presentation is spontaneous pneumothorax, which tends to recur and may be bilateral 
$(5,18)$. The abrupt onset of chest pain or worsening dyspnea in a patient with features of PLCH should always prompt a search for pneumothorax but, as we have seen, chest pain in a patient with PLCH may also be due to rib involvement. Hemoptysis is unusual and should not be attributed to PLCH until the possibility of other etiologies have been excluded $(5,7,16,19)$. Fever, weight loss and malaise are seen in a minority of patients $(6,7,16)$.

The physical examination in PLCH is usually unremarkable, unless there is a pneumothorax or findings suggestive of systemic involvement. Adventitious sounds are uncommon on chest auscultation even in the presence of extensive radiological abnormalities. Clubbing is rare, while signs of pulmonary hypertension and cor pulmonale reflect advanced disease (5).

Advanced PLCH is associated with pulmonary hypertension, which is often more severe than observed in comparably advanced diffuse lung diseases $(20,21)$. Direct involvement of the pulmonary arterioles and venules by the disease process appears to account for this phenomenon, rather than simply a loss of the cross-sectional area of the pulmonary circulation with progressive disease (20). As discussed below, pulmonary vascular dysfunction in PLCH contributes significantly to the exercise limitation experienced in patients with advanced disease (22).

\section{Pulmonary function tests}

Pulmonary function tests in patients with PLCH are variable, with the most common abnormality being a reduced diffusing capacity for carbon monoxide (DLCO) - observed in at least $70 \%$ of patients $(7,16,17,22)$. Most patients also exhibit restrictive, obstructive or mixed ventilatory defects $(6,7,16,17,22)$. Obstruction has occasionally been attributed to smoking-related small airways disease, but it is generally believed that the degree of obstruction observed is out of proportion to smoking history (5) and is more likely due to direct involvement of the small airways by the disease process (see below). Arterial blood gases generally remain within normal limits except when the disease is advanced; however, a widening of the alveolar-arterial oxygen gradient may be detectable on exercise in patients with less advanced disease (22).

A comprehensive study (22) of pulmonary function and exercise physiology in 23 patients with PLCH demonstrated that exercise intolerance in this disease best correlates with resting and exertional indexes of pulmonary vascular involvement. Specifically, the percentage of predicted maximal exercise oxygen consumption was related to decreased DLCO, and to increased resting and exertional dead space to tidal volume ratios. Ventilatory abnormalities, including baseline restriction or obstruction, did not correlate well with exercise limitation.

\section{Radiology}

Bilateral and symmetrical, predominantly upper and mid-lung zone, nodules up to $1 \mathrm{~cm}$ in size are most frequently seen on chest radiographs $(7,10,23)$. The nodules are often irregular in appearance and, with more advanced disease, may extend into the lower lung zones. The costophrenic angles are typically spared in all but the most severe cases. With disease progression, reticular and cystic changes may be observed, and nodules may regress $(7,10)$. Lung volumes are typically normal or increased, and $\mathrm{PLCH}$ is one of the few lung diseases associated with increased interstitial markings and normal or large lung volumes.
High resolution CT (HRCT) may be diagnostic in PLCH, particularly when a combination of cysts and nodules in a characteristic upper lung zone distribution is observed (24). If this pattern is seen in a patient with a typical history, lung biopsy is frequently not required to make the diagnosis. It should be noted, however, that this nearly pathognomonic HRCT pattern is relatively uncommon (7), and that most patients have either cysts or nodules alone.

When only nodules or only cysts are present, the differential diagnosis is broader. Cysts alone may be due to pneumatoceles (eg, from Pneumocystis jirovecii infection), lymphangioleiomyomatosis (LAM) or bronchiectasis. In contrast, the differential diagnosis of the upper zone nodular changes of PLCH includes sarcoidosis, silicosis, tuberculosis or metastatic disease. These latter diagnoses are typically associated with perilymphatic or random distributions of the nodules rather than the more typically centrilobular distribution of $\mathrm{PLCH}$ nodules $(5,10)$. PLCH cysts are usually irregular in shape and are believed to be formed from the coalescence of nodules. As with nodules, sparing of the lung bases is the general rule. Advanced PLCH may progress to honeycombing and fibrotic changes.

\section{DIAGNOSIS}

\section{Role of bronchoscopy}

Bronchoscopy typically reveals normal airways on inspection, but BAL specimens are usually cellular. The differential cell count reveals a preponderance of alveolar macrophages, consistent with the fact that most patients are smokers (25). Occasionally, a slight but nonspecific increase in eosinophil counts may be observed; however, this is an inconsistent finding $(5,25)$.

CD1a, a cell surface marker for LCs, can be identified on cells obtained in BAL fluid using immunostaining (26-28). This test is problematic, however, because CD1a-positive cells can be identified in the BAL fluid of smokers without evidence of interstitial lung disease (29). In addition, many patients with biopsy-proven PLCH lack CD1a-positive cells in BAL fluid. A cut-off of $5 \%$ CD1a-positive cells provides specificity for PLCH, but a very poor sensitivity of only approximately $25 \%$ (5). Additional surface markers, such as langerin (CD207), may improve the usefulness of BAL in diagnosing PLCH in the future (30), but their diagnostic utility has yet to be comprehensively assessed in clinical studies.

Transbronchial lung biopsy has traditionally been considered to have a low yield in the diagnosis of PLCH (31) - a finding confirmed in a recent series of 102 patients with PLCH diagnosed by surgical lung biopsy (7). Therefore, it is useful mainly in the exclusion of other disorders such as sarcoidosis, which may be in the differential diagnosis.

\section{Surgical biopsy}

Surgical biopsy can establish the diagnosis of LCH by demonstrating the presence of characteristic lesions described below. LCH lesions can be found in any tissue involved in the disease process. Hence, in a patient with suspected PLCH and an extrapulmonary lesion with compatible HRCT findings, a biopsy of this lesion may provide the diagnosis.

Nevertheless, because the majority of adults with LCH have isolated PLCH, histopathological confirmation of the diagnosis generally requires a surgical lung biopsy, which can be performed at the time of a pleurodesis for pneumothorax (5). Lung biopsy can generally be avoided when the HRCT findings are 


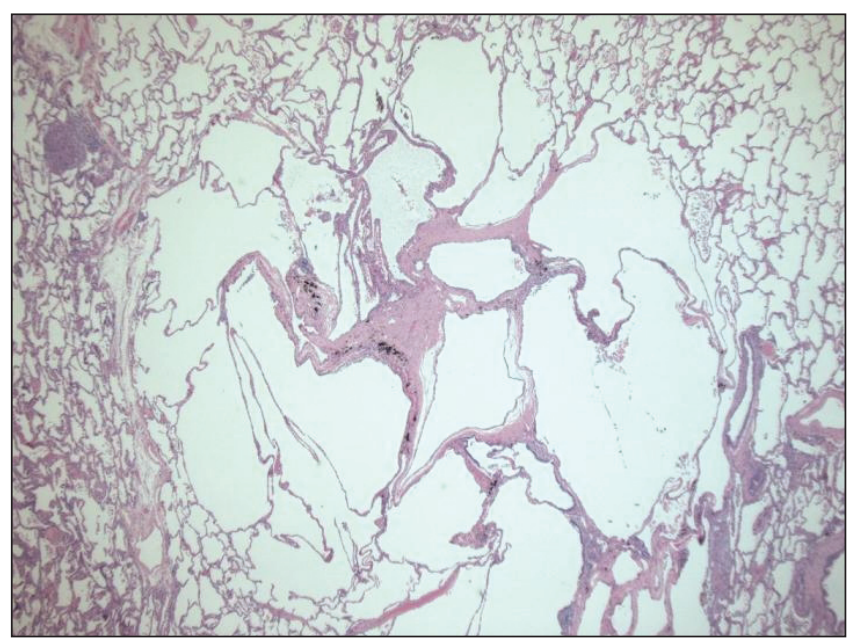

Figure 3) End-stage Langerhans' cell histiocytosis with central stellate scar, adjacent cystic change and surrounding normal lung parenchymal tissue. Hematoxylin and eosin stain, original magnification $\times 16$

characteristic and concordant with the clinical history. In cases in which diagnostic uncertainty remains (eg, a young woman with mainly cystic lung lesions in whom LAM is a consideration), surgical lung biopsy is appropriate.

\section{Pathology}

Gross lung tissue specimens from patients with $\mathrm{PLCH}$ have a variable appearance depending on the stage of disease. Early lesions are focal and white in appearance, with irregular and often stellate borders; they show a predilection for the upper lung zones. In more advanced cases, cavitation and cyst formation is seen. End-stage disease is characterized by fibrosis and honeycomb formation (32).

On microscopic examination, early lesions are centred on terminal and respiratory bronchioles. At the very earliest stage, LCH cells, which stain for CD1a and S100 (although the latter is a nonspecific finding), can be seen infiltrating bronchiolar walls and epithelium. Later, the LCH cells are surrounded by variable numbers of lymphocytes, eosinophils, fibroblasts and plasma cells, progressing to characteristic stellate fibrotic scars enclosed by cystic areas (Figure 3). A key morphological feature of LCH cells that helps to distinguish them from other cells is their highly convoluted nuclear membranes (Figure 4). They also lack prominent nucleoli and have abundant cytoplasm, with poorly-defined borders $(32,33)$. Pigmented macrophages, which are associated with cigarette smoke exposure, are also often seen and, in some cases, may be so extensive as to result in lesions resembling desquamative interstitial pneumonia $(16,32)$, as was seen in our patient. The pulmonary parenchyma between LCH lesions may be normal or may show other smoking-related abnormalities.

LCH lesions progress further by ensheathing the terminal bronchioles - a process that has been demonstrated using three-dimensional reconstructions based on serial histological sections (34). The increasing obstruction of small airways that results from this progression along airways is believed to be responsible for perilesional airspace enlargement and, eventually, cyst formation. Invasion of cords of cells out into the surrounding parenchyma results in the stellate appearance of

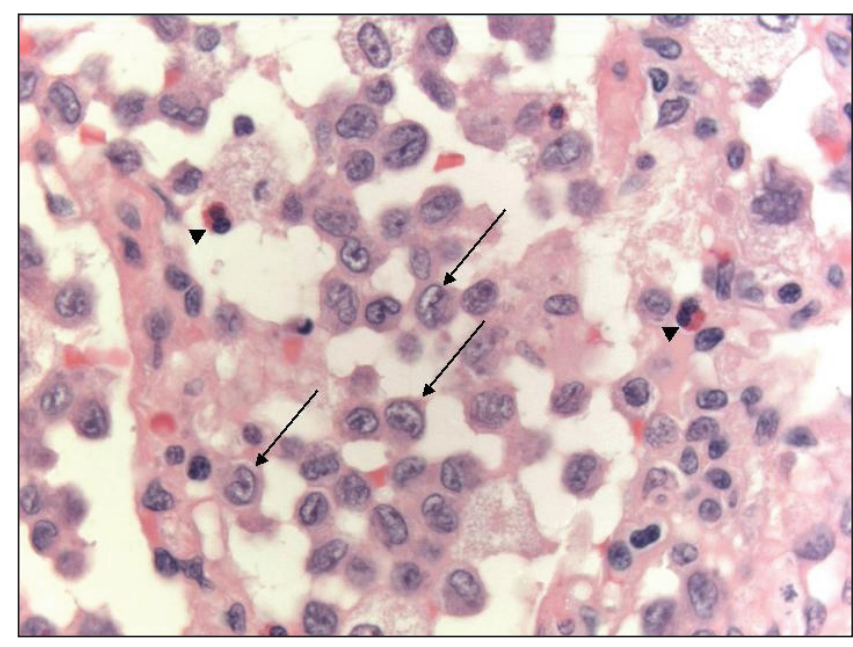

Figure 4) Cellular nodule with aggregates of Langerhans cells demonstrating characteristic kidney bean-shaped nuclei (arrows) and eosinophils (arrowheads) (hematoxylin and eosin stain, original magnification $\times 630)$

the lesions. Over time, the lesions become acellular, leaving behind a fibrous scar, often with the same stellate shape as the original lesion. Although the lesions of PLCH are quite characteristic, in cases in which uncertainty remains, immunohistochemical staining for CD1a is usually sufficient to make the diagnosis (35) (Figure 5).

Electron microscopy can reveal the presence of Birbeck granules, a finding that is specific for LCH cells. Birbeck granules are cytoplasmic, tennis racquet-shaped inclusions (32). Owing to the lower cost and greater efficiency of immunohistochemistry, electron microscopy is no longer routinely used for the diagnosis of PLCH.

\section{BIOLOGY AND PATHOGENESIS OF PLCH}

Despite the strong association of PLCH with smoking, its etiology remains unknown. Unlike pulmonary alveolar proteinosis, there is no animal model of PLCH, making a mechanistic understanding of this disease elusive. Advances in the study of LCs and other DCs have, however, informed our knowledge of the etiopathogenesis of PLCH.

DCs are bone marrow-derived cells that migrate to tissues such as the dermis and lung parenchyma $(36,37)$. In the steady state, DCs reside in these sites and continuously sample antigens in the surrounding microenvironment via macropinocytosis and receptor-mediated endocytosis $(37,38)$. In the absence of additional stimuli, DCs generally promote immune tolerance rather than the initiation of an immune response (39). Inflammatory cytokines, as well as pathogen- or tissue damageassociated molecular motifs (eg, lipopolysaccharide, viral RNA or endogenous proteins released by necrotic cells) bind to and activate pattern-recognition receptors on the DC surface. When this occurs, the DC undergoes a process of maturation, becomes motile and upregulates surface major histocompatibility complex class II and molecules capable of costimulating T cell activation such as CD40, CD80 and CD86 (40). DCs that have been activated in this fashion travel to regional lymph nodes where they present antigenic peptides to $\mathrm{T}$ cells bearing the specific cognate $T$ cell receptor leading to $T$ cell activation 
(41). Hence, DCs act as an important link between the innate and adaptive arms of the immune system.

DCs are divided into two broad categories: myeloid DCs (mDCs) and plasmacytoid DCs. The former arise from myeloid precursors in the bone marrow under the influence of granulocyte-macrophage colony-stimulating factor (GM-CSF) and tumour necrosis factor-alpha (TNF- $\alpha$ ) (42) or interleukin-4 (43). The latter develop in the bone marrow under the influence of a specific growth factor milieu that has not yet been fully characterized (44-48) and are fewer in number than mDCs. LCs are a subset of DCs that develop in response to transforming growth factor-beta (49-51). Their precise relationship to $\mathrm{mDCs}$ and plasmacytoid DCs remains to be clarified, but they exhibit preferential localization to epithelial surfaces such as the epidermis and the tracheobronchial mucosa $(52,53)$. In the steady state, LCs are rare in the distal airways and alveolar interstitium, but can increase in these locations in smokers and in patients with inflammatory lung disorders $(5,32,54)$.

A role for local GM-CSF secretion in the recruitment and/or retention of LCs in these conditions and in PLCH has been suggested. One study (55) revealed that bronchiolar epithelial cells from PLCH-involved areas of the lung secreted more GM-CSF than those from uninvolved areas within the same patient. Additional factors, including interleukin-4 and TNF $\alpha$, are also believed to enhance LC recruitment, proliferation and/or survival. One report (56) of a patient with PLCH who improved dramatically when treated with the TNF- $\alpha$ antagonist etanercept suggests a central role for this cytokine in the pathogenesis of PLCH.

There has been considerable debate as to whether LCs in LCH lesions accumulate as a result of increased cell division or impaired cell death. While LCs in extrapulmonary LCH lesions stain positively for the cell proliferation marker $\mathrm{Ki} 67$ (57), the rate of cell division in the pulmonary lesions has been shown to be rather low, similar to that of bronchial epithelial cells (58). LCs in LCH lesions appear to be resistant to apoptosis $(59,60)$ and exhibit polyclonality $(61)$, indicating that they have not undergone malignant transformation.

LC accumulation in other conditions does not directly cause injury to lung tissue, but appears to be a reactive process. In contrast, LCH granulomas are associated with extensive local tissue destruction in a bronchiolocentric distribution. Importantly, $\mathrm{CD}^{+}{ }^{+} \mathrm{T}$ cells are also prominent within $\mathrm{LCH}$ lesions, and the LCs within the lesions express costimulatory molecules and are in contact with these T cells (62). This observation suggests the formation of an immunological synapse between the LCs - acting as antigen-presenting cells and the $\mathrm{CD}^{+} \mathrm{T}$ cells. Unfortunately, the inability to obtain sufficient numbers of LCs from PLCH lesions for in vitro studies has limited further exploration of this possibility (5).

The presence of $\mathrm{CD}^{+} \mathrm{T}$ cells within $\mathrm{LCH}$ lesions suggests that there may be a specific antigen to which these cells are responding. Viruses, including human herpesvirus 6, have been proposed to be the trigger of the destructive $\mathrm{LCH}$ immune response but conclusive data are lacking (63-65). The close relationship of PLCH and smoking has prompted many investigators to assess whether tobacco-derived antigens contribute to the pathogenesis of PLCH but, surprisingly, peripheral blood lymphocytes from $\mathrm{PLCH}$ patients were less responsive to tobacco

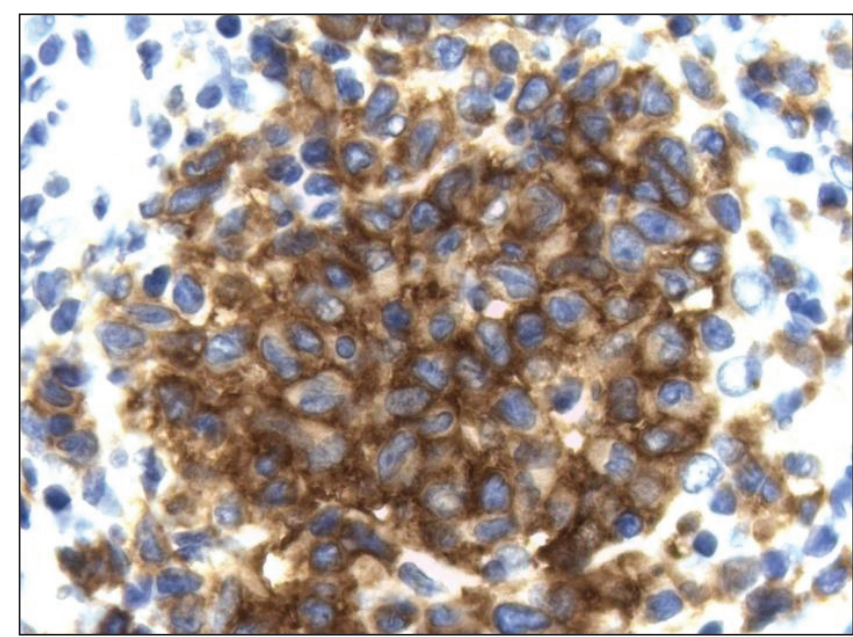

Figure 5) Immunohistochemistry for CD1 a demonstrating strong positive staining in Langerhans cells (original magnification $\times 630$ )

glycoprotein than those of controls (66); nicotine seems to have an inhibitory effect on DC function (67). A third hypothesis, which has not been confirmed, is that tobacco alters the bronchiolar epithelium in a manner that results in the elaboration of new or altered antigens that are presented by lung LCs to CD4 ${ }^{+}$ $\mathrm{T}$ cells (5). This model could explain the early destruction of bronchiolar epithelial cells observed in PLCH.

Any pathogenetic explanation of PLCH must also address the fact that certain individuals develop this unusual disorder while others with similar degrees of exposure to tobacco smoke do not. The importance of extrapulmonary host factors in the development of PLCH is illustrated by the fact that it is known to recur after lung transplantation (68-70). Clearly, there is a great deal that remains to be learned about the pathogenesis of PLCH.

\section{Prognosis}

The course of PLCH is often difficult to predict. In some cases, the disease process becomes quiescent spontaneously or with glucocorticoid therapy, whereas in other cases it progresses inexorably despite smoking cessation and immunosuppressive/cytotoxic drug therapy. A well-designed cohort study (7) of 102 patients with biopsy-proven PLCH reported a median survival of 12.5 years from the time of diagnosis, which was significantly worse than predicted by life tables derived from the general population. Predictors of a poor outcome in PLCH include more advanced cystic changes on HRCT, older age, lower forced expiratory volume in $1 \mathrm{~s}$ to forced vital capacity ratio, higher residual volume to total lung capacity ratio, lower DLCO and the presence of pulmonary hypertension $(6,7,13,20)$. PLCH is associated with an increased risk of both lung cancer and hematological malignancies (7,71-73), with continued smoking being a major risk factor. The major causes of death in PLCH are respiratory failure from progressive disease and malignancy $(6,7)$. Moreover, patients with PLCH experience a poorer health-related quality of life, as measured by the ShortForm-36 Health Survey, than would be expected for an age- and sex-matched population (7). It should be noted, however, that patients with milder or resolving PLCH are often lost to follow-up and, hence, the poor prognosis reported in these longitudinal studies may have been overestimated (5). 


\section{TREATMENT}

No randomized trials of therapy for adult PLCH have yet been reported. Data regarding the effectiveness of interventions for PLCH are derived from observational studies, case reports and expert opinion.

\section{Smoking cessation}

Because the majority of PLCH patients are current or former smokers, it is likely that smoking plays a role in the pathogenesis of the disease. Case reports $(74,75)$ have suggested that this intervention alone may lead to marked improvement or resolution of the disease. However, relapse or worsening despite smoking cessation have also been described (76,77). Nevertheless, because of the high rate of $\mathrm{PLCH}$-associated pulmonary malignancy, the established relationship between smoking and airflow obstruction and many other health benefits, smoking cessation is the most important step in the management of PLCH.

\section{Corticosteroids}

Corticosteroids are frequently used in the management of PLCH despite limited evidence of benefit. A case series (15) of 42 patients with biopsy-proven PLCH showed that the majority of patients treated with corticosteroids improved or remained stable based on clinical and radiographic findings, although improvements in pulmonary function were not observed. Two other studies $(6,17)$ suggested that corticosteroid therapy may be associated with a greater likelihood of deterioration than improvement; however, in both cases, this may have been due to the selection bias inherent in retrospective analysis (78).

Experts suggest that in the absence of evidence of a benefit, corticosteroid therapy should be reserved for symptomatic patients with predominantly nodular lesions on HRCT scans $(5,78)$. They argue that corticosteroids are most likely to be beneficial at this stage of the disease in which inflammatory, rather than fibrotic, lesions are present. A typical corticosteroid dose used in PLCH is $0.5 \mathrm{mg} / \mathrm{kg} / \mathrm{day}$ to $1.0 \mathrm{mg} / \mathrm{kg} / \mathrm{day}$ tapered over six to 12 months $(5,7,78)$.

\section{Cytotoxic drugs}

There is a general consensus that cytotoxic agents are best reserved for patients with multisystem LCH. Drugs that have been used include vinblastine, cyclophosphamide, methotrexate, 2-chlorodeoxyadenosine (cladribine) and etoposide. Most of the data on these agents come from studies in children showing improvement or remission of multisystem LCH (14,79-81). Nevertheless, small case reports and case series $(77,80,82-86)$ suggest that these agents may have a role in the treatment of $\mathrm{LCH}$ with multisystem involvement in adults, including pulmonary disease, although lung-specific indexes of improvement vary.

\section{Pleurodesis and lung transplantation}

Pneumothorax due to PLCH is believed to result from rupture of a cystic lesion. Pleurodesis is generally recommended when pneumothorax occurs because the recurrence rate is high $(5,87)$. In a study by Mendez et al (87), ipsilateral recurrence was as high as $58 \%$ when pneumothorax was treated with tube thoracostomy alone, but was $0 \%$ when pleurodesis was performed. It should be noted that, as is the case with LAM, pleurodesis does not preclude subsequent lung transplantation.

Lung transplantation for PLCH is performed when severe respiratory failure develops. Frequently, pulmonary hypertension is an indication for lung transplantation in PLCH because severe pulmonary hypertension is associated with a higher risk of death (88).

Either single or double-lung transplantation may be performed $(68,69)$. PLCH is known to recur in the allograft following lung transplantation at a rate as high as $20.5 \%$ (69). Risk factors for recurrent disease include the presence of extrapulmonary disease before transplantation, and resumption of smoking following lung transplantation $(69,70)$.

\section{FUTURE THERAPIES}

There is clearly a need for better data regarding extant therapies for PLCH, and a need for less toxic and more effective treatments. In the near term, higher quality data on the value of existing therapies is likely to become available. The Histiocyte Society has initiated a multicentre randomized trial of cytotoxic therapy for multisystem LCH in adults (89). This study aims to test several hypotheses, including whether there is a beneficial effect of smoking cessation and corticosteroid monotherapy on the natural history of PLCH. Additionally, the effect of combination prednisone and vinblastine on clinical outcomes is being assessed.

\section{CONCLUSIONS}

$\mathrm{PLCH}$ is a rare disorder associated with most, but not all, cases involving cigarette smoking. It is frequently progressive and is associated with a higher mortality rate than previously appreciated. Similar to LAM, PLCH is characterized by the accumulation of an unusual cell type with a unique phenotype in the lung parenchyma, and can be associated with extrapulmonary involvement. Whereas LAM probably results in cyst formation as a consequence of peripheral airway constriction caused by LAM cells, leading to a check-valve mechanism, the formation of cysts in PLCH is attributable to airway-centred inflammatory destruction of lung tissue. In contrast to both LAM and pulmonary aleveolar proteinosis, our understanding of the pathogenesis of PLCH is still in its infancy and will require further study of LCs in the context of human tissue and, hopefully, in animal models that reproduce the PLCH phenotype. Presently, smoking cessation, supportive therapy and, in advanced cases, lung transplantation, are the only therapies that can be offered to patients with PLCH. A deeper understanding of the pathogenesis of PLCH will be required before more effective therapies can be developed.

FUNDING: Dr Stephen C Juvet was supported by a Terry Fox Clinical Research Fellowship from the National Cancer Institute of Canada, and by the Clinician-Scientist Training Program, Department of Medicine, University of Toronto (Toronto, Ontario), and by a grant from the National Institutes of Health (HL090669 to Dr Gregory P Downey), and by funds from the Harold and Mary Zirin Chair in Pulmonary Biology at National Jewish Health (Denver, USA). 


\section{REFERENCES}

1. Histiocytosis syndromes in children. Writing Group of the Histiocyte Society. Lancet 1987;1:208-9.

2. Favara BE, Feller AC, Pauli M, et al. Contemporary classification of histiocytic disorders. The WHO Committee On Histiocytic/ Reticulum Cell Proliferations. Reclassification Working Group of the Histiocyte Society. Med Pediatr Oncol 1997;29:157-66.

3. Colby TV, Lombard C. Histiocytosis X in the lung. Hum Pathol 1983;14:847-56.

4. Arico M, Egeler RM. Clinical aspects of Langerhans cell histiocytosis. Hematol Oncol Clin North Am 1998;12:247-58.

5. Tazi A. Adult pulmonary Langerhans' cell histiocytosis. Eur Respir J 2006;27:1272-85

6. Delobbe A, Durieu J, Duhamal A, Wallaert B. Determinants of survival in pulmonary Langerhans' cell granulomatosis (histiocytosis X). Groupe d'Etude en Pathologie Interstitielle de la Societe de Pathologie Thoracique du Nord. Eur Respir J 1996;9:2002-6.

7. Vassallo R, Ryu J, Schroeder DR, Decker PA, Limper AH. Clinical outcomes of pulmonary Langerhans'-cell histiocytosis in adults. N Engl J Med 2002;346:484-90.

8. Carstensen H, Ornvold K. The epidemiology of Langerhans cell histiocytosis in Denmark, 1975-89. Med Pediatr Oncol 1993;21:387-8.

9. Baumgartner I, von Hochstetter A, Baumert B, Leutolf B, Follath F. Langerhans'-cell histiocytosis in adults. Med Pediatr Oncol 1997;28:9-14.

10. Abbott GF, Rosado-de-Christenson ML, Franks TJ, Frazier AA, Galvin JR. From the archives of the AFIP: Pulmonary Langerhans cell histiocytosis. Radiographics 2004;24:821-41.

11. Gaensler EA, Carrington CB. Open biopsy for chronic diffuse infiltrative lung disease: Clinical, roentgenographic, and physiological correlations in 502 patients. Ann Thorac Surg 1980;30:411-26.

12. Thomeer M, Demedts M, Vandeurzen K. Registration of interstitial lung diseases by 20 centres of respiratory medicine in Flanders. Acta Clin Belg 2001;56:163-72.

13. Basset F, Corrin B, Spencer H, et al. Pulmonary histiocytosis X. Am Rev Respir Dis 1978;118:811-20.

14. Howarth DM, Gilchrist GS, Mullan BP, Wiseman GA, Edmonson JH, Schomberg PJ. Langerhans cell histiocytosis: Diagnosis, natural history, management, and outcome. Cancer 1999;85:2278-90

15. Schonfeld N, Frank W, Wenig S, et al. Clinical and radiologic features, lung function and therapeutic results in pulmonary histiocytosis X. Respiration 1993;60:38-44.

16. Travis WD, Borok Z, Roum JH, et al. Pulmonary Langerhans cell granulomatosis (histiocytosis X). A clinicopathologic study of 48 cases. Am J Surg Pathol 1993;17:971-86.

17. Watanabe R, Tatsumi K, Hashimoto S, Tamakoshi A, Kuriyama T; Respiratory Failure Research Group of Japan. Clinico-epidemiological features of pulmonary histiocytosis X. Intern Med 2001;40:998-1003.

18. Friedman PJ, Liebow AA, Sokoloff J. Eosinophilic granuloma of lung. Clinical aspects of primary histiocytosis in the adult. Medicine (Baltimore) 1981;60:385-96.

19. Knight RK, Haemoptysis in eosinophilic granuloma. Br J Dis Chest 1979;73:181-6.

20. Fartoukh M, Humbert M, Capron F, et al. Severe pulmonary hypertension in histiocytosis X. Am J Respir Crit Care Med 2000;161:216-23.

21. Harari S, Brenot F, Barberis M, Simmoneau G. Advanced pulmonary histiocytosis $\mathrm{X}$ is associated with severe pulmonary hypertension. Chest 1997;111:1142-4

22. Crausman RS, Jennings CA, Tuder RM, Ackerson LM, Irvin CG, King TE Jr. Pulmonary histiocytosis X: Pulmonary function and exercise pathophysiology. Am J Respir Crit Care Med 1996;153:426-35.

23. Lacronique J, Roth C, Battesti JP, Basset F, Chretien J. Chest radiological features of pulmonary histiocytosis X: A report based on 50 adult cases. Thorax 1982;37:104-9.

24. Grenier P, Valeyre D, Cluzel P, Brauner MW, Lenoir S, Chastang C. Chronic diffuse interstitial lung disease: Diagnostic value of chest radiography and high-resolution CT. Radiology 1991;179:123-32.

25. Hance AJ, Basset F, Saumon G, et al. Smoking and interstitial lung disease. The effect of cigarette smoking on the incidence of pulmonary histiocytosis X and sarcoidosis. Ann N Y Acad Sci 1986;465:643-56.
26. Auerswald U, Barth J, Magnussen H. Value of CD-1-positive cells in bronchoalveolar lavage fluid for the diagnosis of pulmonary histiocytosis X. Lung 1991;169:305-9.

27. Chollet S, Soler P, Dournovo P, Richard MS, Ferrans VJ, Basset F. Diagnosis of pulmonary histiocytosis $\mathrm{X}$ by immunodetection of Langerhans cells in bronchoalveolar lavage fluid. Am J Pathol 1984;115:225-32.

28. Xaubet A, Agustí C, Picado C, et al. Bronchoalveolar lavage analysis with anti-T6 monoclonal antibody in the evaluation of diffuse lung diseases. Respiration 1989;56:161-6.

29. Casolaro MA, Bernaudin JF, Saltini C, Ferrans VJ, Crystal RG. Accumulation of Langerhans' cells on the epithelial surface of the lower respiratory tract in normal subjects in association with cigarette smoking. Am Rev Respir Dis 1988;137:406-11.

30. Smetana K Jr, Mericka O, Saeland S, Homolka J, Brabec J, Gabius HJ. Diagnostic relevance of Langerin detection in cells from bronchoalveolar lavage of patients with pulmonary Langerhans cell histiocytosis, sarcoidosis and idiopathic pulmonary fibrosis. Virchows Arch 2004;444:171-4.

31. Housini I, Tomashefski JF Jr, Cohen A, Crass J, Kleinerman J. Transbronchial biopsy in patients with pulmonary eosinophilic granuloma. Comparison with findings on open lung biopsy. Arch Pathol Lab Med 1994;118:523-30.

32. Myers JL. In: Thurlbeck's Pathology of the Lung, AM Churg, et al, eds. Other Diffuse Lung Diseases. New York: Thieme, 2005:601-73.

33. Lieberman PH, Jones CR, Steinman RM, et al. Langerhans cell (eosinophilic) granulomatosis. A clinicopathologic study encompassing 50 years. Am J Surg Pathol 1996;20:519-52.

34. Kambouchner M, Basset F, Marchal J, Uhl JF, Hance AJ, Soler P. Three-dimensional characterization of pathologic lesions in pulmonary langerhans cell histiocytosis. Am J Respir Crit Care Med 2002;166:1483-90.

35. Emile JF, Wechsler J, Brousse N, et al. Langerhans' cell histiocytosis. Definitive diagnosis with the use of monoclonal antibody $\mathrm{O} 10$ on routinely paraffin-embedded samples. Am J Surg Pathol 1995;19:636-41.

36. Lambrecht BN, JB Prins JB, Hoogsteden HC. Lung dendritic cells and host immunity to infection. Eur Respir J 2001;18:692-704.

37. Steinman RM, Dendritic cells: Understanding immunogenicity. Eur J Immunol 2007;37(Suppl 1):S53-60.

38. Reis e Sousa C, Stahl PD, Austyn JM. Phagocytosis of antigens by Langerhans cells in vitro. J Exp Med 1993;178:509-19.

39. Hawiger D, Inaba K, Dorsett $Y$, et al. Dendritic cells induce peripheral T cell unresponsiveness under steady state conditions in vivo. J Exp Med 2001;194:769-79.

40. Mellman I, Steinman RM. Dendritic cells: Specialized and regulated antigen processing machines. Cell 2001;106:255-8.

41. Lanzavecchia A, Sallusto F. Regulation of T cell immunity by dendritic cells. Cell 2001;106:263-6.

42. Caux C, Dezutter-Dambuyant C, Schmitt D, Banchereau J. GM-CSF and TNF-alpha cooperate in the generation of dendritic Langerhans cells. Nature 1992;360:258-61.

43. Banchereau J, Briere F, Caux C, et al. Immunobiology of dendritic cells. Annu Rev Immunol 2000;18:767-811.

44. Nagasawa M, Schmidlin H, Hazekamp MG, Schotte R, Blom B. Development of human plasmacytoid dendritic cells depends on the combined action of the basic helix-loop-helix factor E2-2 and the Ets factor Spi-B. Eur J Immunol 2008;38:2389-400.

45. Naik SH, Sathe P, Park HY, et al. Development of plasmacytoid and conventional dendritic cell subtypes from single precursor cells derived in vitro and in vivo. Nat Immunol 2007;8:1217-26.

46. Olivier A, Lauret E, Gonin P, Galy A. The Notch ligand delta-1 is a hematopoietic development cofactor for plasmacytoid dendritic cells. Blood 2006;107:2694-701.

47. Tsujimura H, Tamura T, Ozato K, Cutting edge: IFN consensus sequence binding protein/IFN regulatory factor 8 drives the development of type I IFN-producing plasmacytoid dendritic cells. J Immunol 2003;170:1131-5.

48. Shortman K, Naik SH. Steady-state and inflammatory dendritic-cell development. Nat Rev Immunol 2007;7:19-30.

49. Caux C, Massacrier C, Dubois B, et al. Respective involvement of TGF-beta and IL-4 in the development of Langerhans cells and non-Langerhans dendritic cells from CD34+ progenitors. J Leukoc Biol 1999;66:781-91. 
50. Geissmann F, Prost C, Monnet JP, Dy M, Brousse N, Hermine O. Transforming growth factor betal, in the presence of granulocyte/ macrophage colony-stimulating factor and interleukin 4, induces differentiation of human peripheral blood monocytes into dendritic Langerhans cells. J Exp Med 1998;187:961-6.

51. Zhang Y, Zhang YY, Ogata M, et al. Transforming growth factorbetal polarizes murine hematopoietic progenitor cells to generate Langerhans cell-like dendritic cells through a monocyte/ macrophage differentiation pathway. Blood 1999;93:1208-20.

52. Hance AJ. Pulmonary immune cells in health and disease: Dendritic cells and Langerhans' cells. Eur Respir J 1993;6:1213-20.

53. Holt PG. Antigen presentation in the lung. Am J Respir Crit Care Med 2000;162(4 Pt 2):S151-6.

54. Zeid NA, Muller HK. Tobacco smoke induced lung granulomas and tumors: Association with pulmonary Langerhans cells. Pathology 1995;27:247-54.

55. Tazi A, Bonay M, Bergeron A, Grandsaigne M, Hance AJ, Soler P. Role of granulocyte-macrophage colony stimulating factor (GM-CSF) in the pathogenesis of adult pulmonary histiocytosis X. Thorax 1996;51:611-4.

56. Henter JI, Karlén J, Calming U, Bernstrand C, Andersson U, Fadeel B. Successful treatment of Langerhans'-cell histiocytosis with etanercept. N Engl J Med 2001;345:1577-8.

57. Schouten B, Egeler RM, Leenen PJ, Taminiau AH, van den Broek LJ, Hogendoorn PC. Expression of cell cycle-related gene products in Langerhans cell histiocytosis. J Pediatr Hematol Oncol 2002;24:727-32.

58. Brabencova E, Tazi A, Lorenzato M, et al. Langerhans cells in Langerhans cell granulomatosis are not actively proliferating cells. Am J Pathol 1998;152:1143-9.

59. Marchal J, Kambouchner M, Tazi A, Valeyre D, Soler P. Expression of apoptosis-regulatory proteins in lesions of pulmonary Langerhans cell histiocytosis. Histopathology 2004;45:20-8.

60. Savell VH Jr, Sherman T, Scheuermann RH, Siddiqui AM, Margraf LR. Bcl-2 expression in Langerhans' cell histiocytosis. Pediatr Dev Pathol 1998;1:210-5.

61. Yousem SA, Colby TV, Chen YY, Chen WG, Weiss LM. Pulmonary Langerhans' cell histiocytosis: Molecular analysis of clonality. Am J Surg Pathol 2001;25:630-6.

62. Tazi A, Bonay M, Grandsaigne M, Battesti JP, Hance AJ, Soler P. Surface phenotype of Langerhans cells and lymphocytes in granulomatous lesions from patients with pulmonary histiocytosis X. Am Rev Respir Dis 1993;147(6 Pt 1):1531-6.

63. Glotzbecker MP, Carpentieri DF, Dormans JP. Langerhans cell histiocytosis: A primary viral infection of bone? Human herpes virus 6 latent protein detected in lymphocytes from tissue of children. J Pediatr Orthop 2004;24:123-9.

64. Leahy MA, Krejci SM, Friednash M, et al. Human herpesvirus 6 is present in lesions of Langerhans cell histiocytosis. J Invest Dermatol 1993;101:642-5.

65. Slacmeulder M, Geissmann F, Lepelletier Y, et al. No association between Langerhans cell histiocytosis and human herpes virus 8 . Med Pediatr Oncol 2002;39:187-9.

66. Youkeles LH, Grizzanti JN, Liao Z, Chang CJ, Rosenstreich DL. Decreased tobacco-glycoprotein-induced lymphocyte proliferation in vitro in pulmonary eosinophilic granuloma. Am J Respir Crit Care Med 1995;151:145-50.

67. Nouri-Shirazi M, Guinet E. Evidence for the immunosuppressive role of nicotine on human dendritic cell functions. Immunology 2003;109:365-73.

68. Boehler A. Lung transplantation for cystic lung diseases: Lymphangioleiomyomatosis, histiocytosis $\mathrm{X}$, and sarcoidosis. Semin Respir Crit Care Med 2001;22:509-16.
69. Dauriat G, Mal H, Thabut G, et al. Lung transplantation for pulmonary langerhans' cell histiocytosis: A multicenter analysis. Transplantation 2006;81:746-50.

70. Etienne B, Bertocchi M, Gamondes JP, et al. Relapsing pulmonary Langerhans cell histiocytosis after lung transplantation. Am J Respir Crit Care Med 1998;157:288-91.

71. Lombard CM, Medeiros LJ, Colby TV. Pulmonary histiocytosis X and carcinoma. Arch Pathol Lab Med 1987;111:339-41.

72. Sadoun D, Vaylet F, Valeyre D, et al. Bronchogenic carcinoma in patients with pulmonary histiocytosis X. Chest 1992;101:1610-3.

73. Tomashefski JF, Khiyami A, Kleinerman J. Neoplasms associated with pulmonary eosinophilic granuloma. Arch Pathol Lab Med 1991;115:499-506.

74. Mogulkoc N, Veral A, Bishop PW, Bayindir U, Pickering CA, Egan JJ. Pulmonary Langerhans' cell histiocytosis: Radiologic resolution following smoking cessation. Chest 1999;115:1452-5.

75. Von Essen S, West W, Sitorius M, Rennard SI. Complete resolution of roentgenographic changes in a patient with pulmonary histiocytosis X. Chest 1990;98:765-7.

76. Tazi A, Montcelly L, Bergeron A, Valeyre D, Battesti JP, Hance AJ. Relapsing nodular lesions in the course of adult pulmonary Langerhans cell histiocytosis. Am J Respir Crit Care Med 1998;157(6 Pt 1):2007-10.

77. Konno S, Hizawa N, Betsuyaku T, et al. Adult Langerhans cell histiocytosis with independently relapsing lung and liver lesions that was successfully treated with etoposide. Intern Med 2007;46:1231-5.

78. Tazi A, Soler P, Hance AJ. Adult pulmonary Langerhans' cell histiocytosis. Thorax 2000;55:405-16.

79. Gadner H, Grois N, Arico M, et al. A randomized trial of treatment for multisystem Langerhans' cell histiocytosis. J Pediatr 2001;138:728-34.

80. Gadner H, Grois N, Pötschger U, et al. Improved outcome in multisystem Langerhans cell histiocytosis is associated with therapy intensification. Blood 2008;111:2556-62.

81. Yagci B, Varan A, Altinok G, Söylemezoglu F, Cila A, Büyükpamukçu M. Langerhans cell histiocytosis: Retrospective analysis of 217 cases in a single center. Pediatr Hematol Oncol 2008;25:399-408.

82. Aerni MR, Aubry MC, Myers JL, Vassallo R. Complete remission of nodular pulmonary Langerhans cell histiocytosis lesions induced by 2-chlorodeoxyadenosine in a non-smoker. Respir Med 2008;102:316-9.

83. Goh NS, McDonald CE, MacGregor DP, Pretto JJ, Brodie GN. Successful treatment of Langerhans cell histiocytosis with 2-chlorodeoxyadenosine. Respirology 2003;8:91-4.

84. Pardanani A, Phyliky RL, Li CY, Tefferi A. 2-Chlorodeoxyadenosine therapy for disseminated Langerhans cell histiocytosis. Mayo Clin Proc 2003;78:301-6.

85. Saven A, Burian C. Cladribine activity in adult langerhans-cell histiocytosis. Blood 1999;93:4125-30.

86. Schulze J, Kitz R, Grüttner HP, Schmidt H, Zielen S. Severe isolated pulmonary Langerhans cell histiocytosis in a 6-year-old girl. Eur J Pediatr 2004;163:320-2.

87. Mendez JL, Nadrous HF, Vassallo R, Decker PA, Ryu JH. Pneumothorax in pulmonary Langerhans cell histiocytosis. Chest 2004;125:1028-32.

88. Chaowalit N, Pellikka PA, Decker PA, et al. Echocardiographic and clinical characteristics of pulmonary hypertension complicating pulmonary Langerhans cell histiocytosis. Mayo Clin Proc 2004;79:1269-75.

89. Arico M. Langerhans cell histiocytosis in adults: More questions than answers? Eur J Cancer 2004;40:1467-73. 


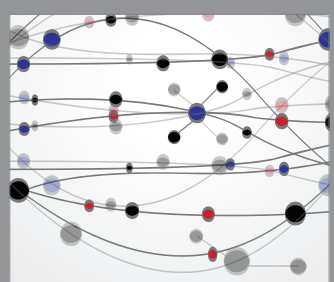

The Scientific World Journal
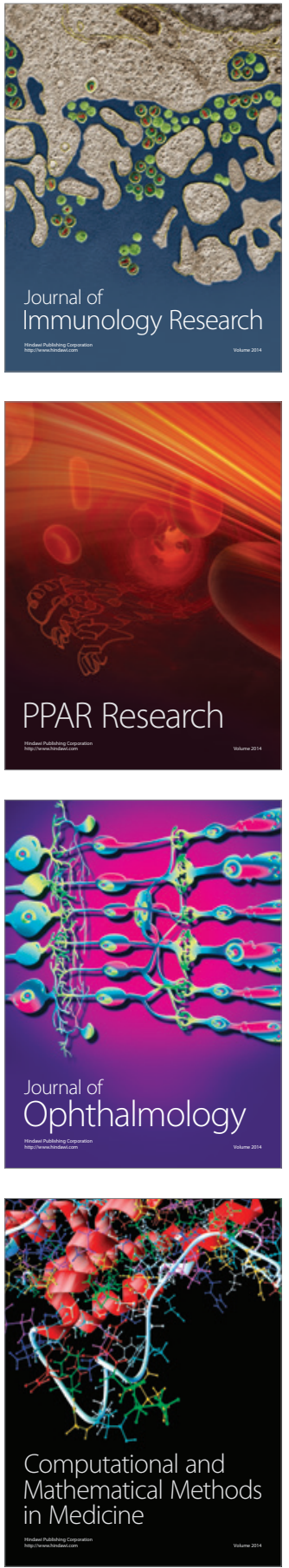

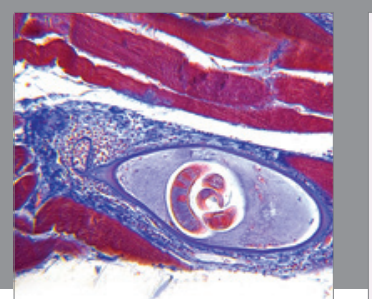

Gastroenterology Research and Practice

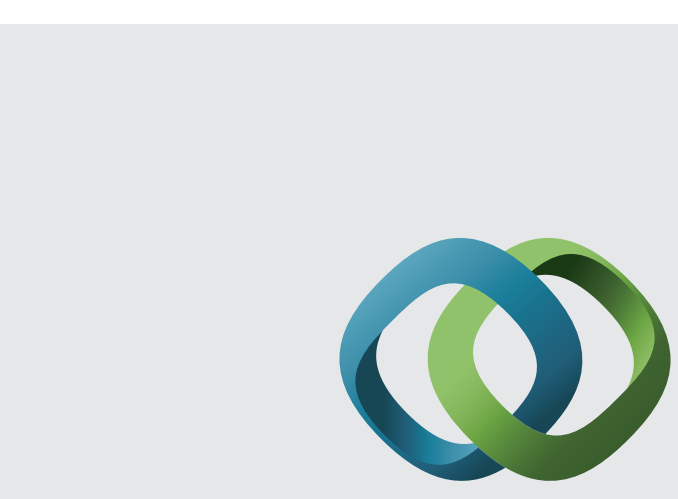

\section{Hindawi}

Submit your manuscripts at

http://www.hindawi.com
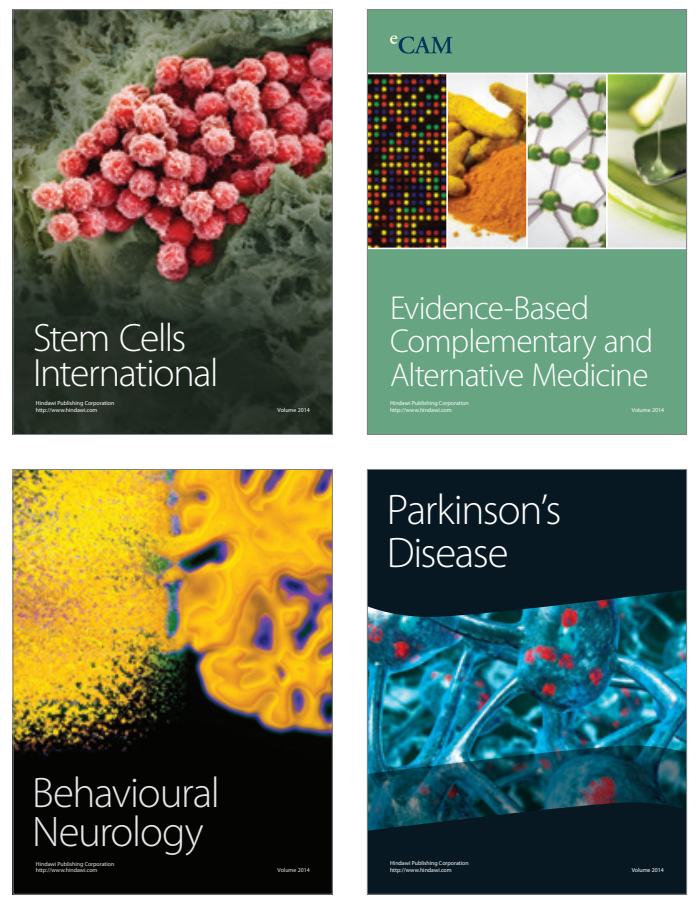
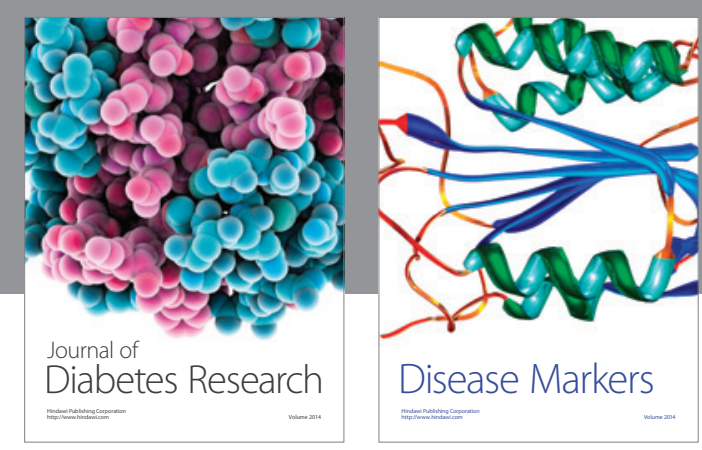

Disease Markers
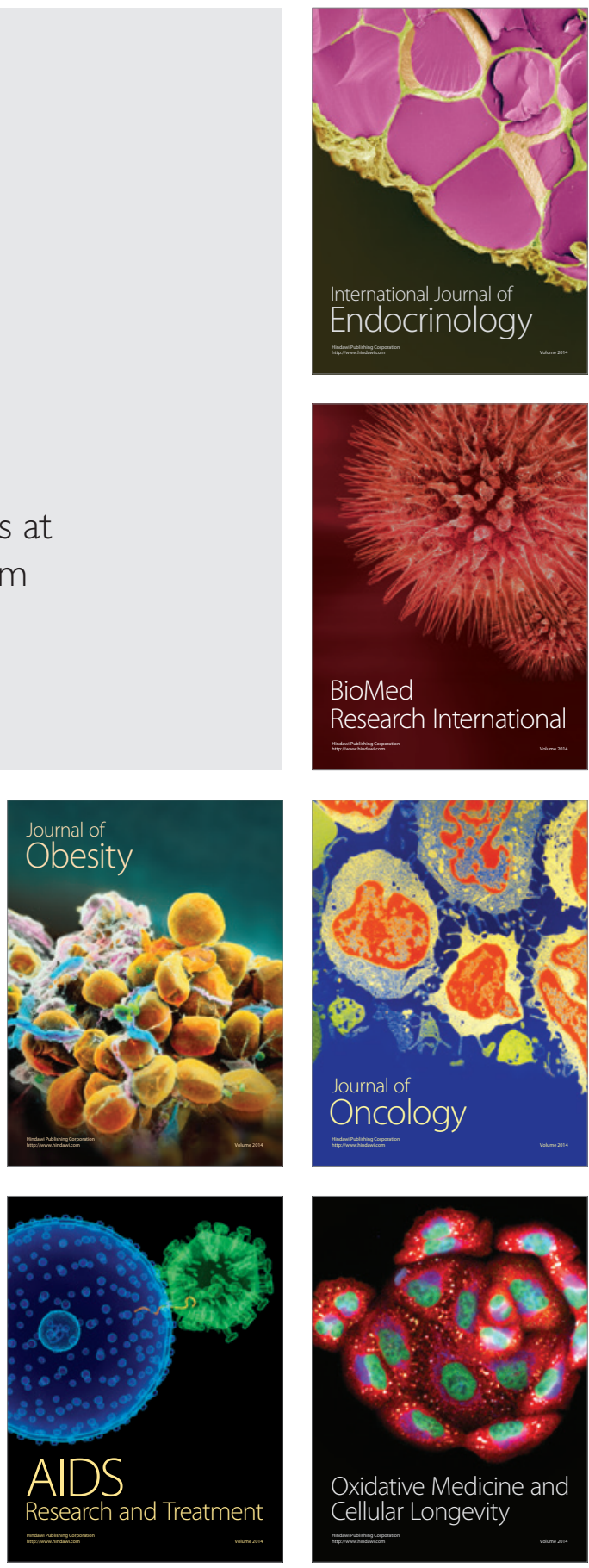